\title{
Audit Energi Listrik Berbasis Hasil Pengukuran Dan Monitoring Besaran Listrik Pada Gedung A Fakultas Teknik Unila
}

\author{
Dikpride Despa $^{1,2}$, Gigih Forda Nama ${ }^{3}$, Trisya Septiana ${ }^{4}$, Muhammad Bayu Saputra $^{5}$ \\ ${ }^{1,4}$ Program Studi Teknik Elektro Universitas Lampung, Bandar Lampung \\ ${ }^{2}$ Program Studi Program Profesi Insinyur Universitas Lampung, Bandar Lampung \\ ${ }^{3,4}$ Program Studi Teknik Informatika, Universitas Lampung, Bandar Lampung \\ Jl. Prof. Sumantri Brojonegoro No.1 Bandar Lampung 35145 \\ 1,2despa@eng.unila.ac.id \\ ${ }^{3}$ gigih@eng.unila.ac.id \\ ${ }^{4}$ trisya.septiana@eng.unila.ac.id \\ ${ }^{5} \mathrm{~m}$.bayusaputra1529estudent.unila.ac.id
}

Intisari - Gedung A Fakultas Teknik Unila berlokasi di Jalan S. Brojonegoro No. 1 Bandar Lampung. Penggunaan energi listrik pada gedung A ini tidak tercatat secara pasti karena memang belum tersedia Kwh Meter tersendiri pada Gedung, sehingga tidak dapat dipastikan apakah penggunaan energi sudah efisien atau belum. Untuk itu perlu dilakukan audit penggunaan energi listrik guna mengetahui nilai Intensitas Konsumsi Energi (IKE) yang memberikan informasi tingkat efisiensi penggunaan energinya.

Pengukuran konsumsi energi secara langsung adalah metode audit yang dilakukan pada penelitian ini untuk mendapatkan nilai aktual dan peluang dalam rangka konservasi dan efisiensi energi. Dari hasil pengukuran diperoleh nilai IKE adalah $9,487 \mathrm{kwh} / \mathrm{m}^{2} /$ bulan dan termasuk kategori efisien untuk gedung ber AC menurut Peraturan Menteri ESDM No.13 Tahun 2012, namun demikian beberapa peralatan penggunaannya masih boros energi sehingga dimungkinkan adanya peluang yang dapat dilakukan untuk menjadi lebih efisien. Rekomendasi yang diberikan berkenaan dengan hasil audit dan temuan di lapangan adalah dengan menggunakan peralatan peralatan hemat energi, mengatur suhu ruangan yang tidak melebihi $10 \%$ lebih rendah dari suhu diluar ruangan, melakukan perawatan berkala terhadap peralatan listrik, menutup jendela ketika AC sedang nyala, memasang door closer pada pintu utama serta disiplin dalam pengoperasian peralatan listrik. Rekomendasi ini dapat menurunkan nilai IKE menjadi $8,424 \mathrm{kwh} / \mathrm{m}^{2} / \mathrm{bulan}$ (sangat efisien).

Kata kunci - Audit Energi, IKE, Bangunan Gedung FT-Unila, Efisiensi Energi

Abstract - A building Faculty of Engineering Unila is located at Jalan S. Brojonegoro No. 1 Bandar Lampung. The use of electrical energy in A building is not recorded definitively because it's not available kwh meter in building it's own, so it can't be ascertained whether the use of energy is efficient or not. Therefore, it is necessary to audit the use of electrical energy in order to know the value of Energy Consumption Intensity (IKE) that provides information on the level of energy efficiency. Energy audits on buildings not only provide efficient level of information, but also provide recommendations for actions that can be taken to achieve efficient value without compromising the sense of comfort in conducting activities in the space in each audited building. Direct measurement of energy consumption is an audit method conducted in this research to obtain actual value and opportunities in the framework of energy conservation and efficiency. From the measurement obtained IKE value is $9,487 \mathrm{kwh} / \mathrm{m} 2 / \mathrm{month}$ and belongs to the efficient category for air-conditioned buildings according to Regulation of the Minister of Energy and Mineral Resources No.13 of 2012, but nevertheless some equipment use is still wasteful of energy so that there are possible opportunities that can be done to be more efficient. Recommendations given with regard to the results of audits and findings in the field are to use energy efficient equipment, regulate room temperature that does not exceed $10 \%$ lower than the outdoor temperature, perform periodic maintenance of electrical equipment, close windows when the air conditioner is on, install door closers on the main door and discipline in the operation of electrical equipment. This recommendation can reduce the value of IKE to 8,424 $\mathrm{kwh} / \mathrm{m} 2 /$ month (very efficient).

Keywords - Energy Audit, IKE, the building of FT-Unila, energy eficiency 


\section{PENDAHULUAN}

Pemerintah memiliki komitmen yang tegas dalam melakukan proses konservasi energi pada bangunan-bangunan di Indonesia. Hal ini dibuktikan dengan adanya rencana pengelolaan energi untuk memenuhi kebutuhan energi nasional berdasarkan kebijakan pengelolaan energi jangka panjang dalam bentuk UndangUndang maupun Peraturan Pemerintah dan Menteri terkait; seperti Undang-Undang No. 30 Tahun 2007, tentang Energi[1]; Peraturan Pemerintah No. 70 Tahun 2009, tentang Konservasi Energi; Peraturan Menteri ESDM No. 13 Tahun 2012 ,tentang Penghematan Pemakaian Tenaga Listrik dengan target penghematan tata cara penghematan, gugus tugas pengawasan dan juga pelaporan[2]. Dan juga Peraturan Menteri ESDM No. 14 Tahun 2012, tentang Manajemen Energi mengenai klasifikasi pengguna energi dan tata cara pelaksanaan manajemen energi[3].

Konservasi energi merupakan langkah kebijaksanaan yang pelaksanaannya paling mudah dan biayanya paling murah diantara langkah-langkah lainnya, serta dapat dilaksanakan oleh seluruh lapisan masyarakat. Konservasi energi tidak boleh menjadi penghambat kerja operasional maupun pembangunan yang telah direncanakan. Audit Energi adalah teknik yang dipakai untuk menghitung besarnya konsumsi energi pada bangunan gedung dan mengenali cara-cara untuk penghematannya [4]. Saat ini energi listrik telah menjadi bagian penting dalam kehidupan masyarakat modern [5] termasuk Perguruan Tinggi dalam hal ini Universitas Lampung.Gedung A Fakultas Teknik Unila (FT-UNILA) merupakan salah satu gedung yang terdapat di Universitas Lampung yang sampai saat ini belum memiliki informasi berkenaan dengan penggunaan energinya. Padahal data ini sangat penting dalam rangka memberikan informasi apakah sebuah gedung efisien dalam penggunaan energinya. Audit Energi bangunan Gedung di Universitas Lampung sudah dilakukan pada beberapa gedung di Unila[6]. Dari Penelitian yang dilakukan diperoleh nilai Intensitas Konsumsi Energi
(IKE) yang merupakan besaran tingkat konsumsi energi listrik pada kurun waktu tertentu dengan satuan luas bangunan yang relatif efisien dan sedikit boros. Selain itu hasil pengukuran besaran listrik di Universitas Lampung cenderung bervariasi terkadang melebihi batas standar yang di izinkan[7]. Berbagai permasalahan berkenaan dengan pengelolaan energi hampir sama pada semua gedung yang diaudit, yaitu hampir semua gedung selain boros juga masih belum memberikan kenyamanan dan cenderung tidak sesuai standar Nasional Indonesia (SNI). Audit energi listrik pada Gedung A FT-UNILA ini dilakukan dalam rangka mengetahui pola penggunaan energi serta mengetahui nilai IKE dan memberikan rekomendasi dalam rangka konservasi dan efisiensi energi listrik. Rekomendasi yang diberikan dapat memperkecil nilai IKE yang berarti dapat meningkatkan efisiensi penggunaan energinya.

\section{A. Audit Energi}

Audit Energi bertujuan untuk memperoleh nilai Intensitas Konsumsi Energi (IKE)[8].Secara sederhana dijelaskan bahwa untuk menghitung nilai IKE dapat dituliskan dalam persamaan:

$I K E=\frac{\text { Total Konsumsi Energi }(\mathrm{kwh})}{\text { Luas Area }(\mathrm{m} 2)}$

Menurut Peraturan Menteri ESDM No.13 Tahun 2012 kriteria penggunaan energi di gedung perkantoran berdasarkan konsumsi energi listrik spesifik $\left(\mathrm{kWh} / \mathrm{m}^{2} /\right.$ bulan $)$ dapat mengacu pada tabel 1 berikut ini :

Tabel 1. Kriteria Penggunaan Energi

\begin{tabular}{|l|l|l|l|}
\hline \multicolumn{2}{|c|}{$\begin{array}{c}\text { Ruangan dengan AC } \\
(\mathbf{k W h} / \mathbf{m} \text { 2/bulan) }\end{array}$} & \multicolumn{2}{c|}{$\begin{array}{c}\text { Ruangan tanpa AC } \\
\text { (kWh/m2/bulan) }\end{array}$} \\
\hline $\begin{array}{l}\text { Sangat } \\
\text { Efisien }\end{array}$ & $<8,5$ & $\begin{array}{l}\text { Sangat } \\
\text { Efisien }\end{array}$ & $<3,4$ \\
\hline Efisien & $\begin{array}{l}=8,5 \text { sampai } \\
<14\end{array}$ & Efisien & $\begin{array}{l}=3,4 \text { sampai } \\
<5,6\end{array}$ \\
\hline $\begin{array}{l}\text { Cukup } \\
\text { efisien }\end{array}$ & $\begin{array}{l}=14 \text { sampai } \\
<18,5\end{array}$ & $\begin{array}{l}\text { Cukup } \\
\text { efisien }\end{array}$ & $\begin{array}{l}=5,6 \text { sampai } \\
<7,4\end{array}$ \\
\hline Boros & $\geq 18,5$ & Boros & $\geq 7,4$ \\
\hline
\end{tabular}


Berdasarkan tabel 1. di atas, apabila hasil perhitungan IKE dalam batas kisaran yang ditetapkan maka penggunaan energi masih dalam tingkat kewajaran. Namun, apabila nilai IKE melebihi batas maka diperlukan tindakan penghematan energi.

\section{B. Pengukuran Besaran listrik}

Arus listrik dapat dirumuskan dengan persamaan berikut[9].

$$
I=\frac{d Q}{d t}
$$

Sementara tegangan didefinisikan sebagai kerja yang diperlukan untuk memindahkan satu unit muatan dari satu terminal ke terminal yang lain :

$$
V=\frac{d W}{d Q}
$$

Dimana : $\mathrm{V}=$ Tegangan (Volt), $\mathrm{W}=$ Energi

(J) dan Q = Muatan Listrik.

\section{Energi Listrik}

Energi listrik adalah daya listrik yang terpakai selama waktu tertentu. Besarnya energi listrik yang digunakan pada peralatan listrik sebanding dengan hasil kali antara tegangan listrik (V), arus listrik (I), dan Jika ditulis dalam persamaan matematis adalah sebagai berikut :

$W=V . I . t$

\section{METODOLOGI}

\section{A. Lokasi Penelitian}

Penelitian ini adalah merupakan penelitian studi kasus yang dilakukan di gedung A FTUNILA yang berlokasi Jalan Prof. S. Brojonegoro No. 1, Bandar Lampung, Lampung. Bangunan ini terdiri 2 lantai. yang berfungsi sebagai kantor Dekan, Wakil Dekan Bidang Akademik dan kerjasama, Wakil Dekan II Bidang Administrasi Umum dan Keuangan, Wakil Dekan Bidang Kemahasiswaan dan Alumni. Fungsi lain dari Dekanat ini adalah untuk kantor TPMPF, Kantor TU FT, akademik, kemahasiswaan, Kepegawaian, umum dan keuangan serta PS PPI FT Unila.
Luas bangunan gedung ini mencapai \pm $1143 \mathrm{~m}^{2}$. Sumber energi listrik yang digunakan pada gedung berasal dari PLN dengan kontrak daya 3 phasa sebesar $66 \mathrm{kVA}$ dengan tegangan 380 Volt dan golongan tarif P2. Jam operasional gedung adalah hari Senin sampai Jumat dari jam 08.00 WIB sampai dengan 16.00 WIB, sedangkan untuk hari sabtu, minggu, dan hari libur nasional dapat dianggap tidak ada opersional pada gedung tersebut, karena hanya beberapa lampu penerangan yang nyala pada saat malam hari. Pengguna energi utama dan terbanyak adalah AC, selanjutnya diikuti oleh beban peralatan kantor seperti komputer, printer, dispenser, televisi, peralatan lainnya dan penerangan. Untuk mengendalikan operasional peralatan masih menggunakan sistem operasi manual. Pengoperasian peralatan tersebut secara umum menjadi tanggung jawab bagian pada masing-masing bagian/divisi yang ada di kantor tersebut.

\section{B. Peralan Pendukung}

Untuk mendukung kegiatan audit energi yang dilakukan di Gedung A FT-UNILA beberapa instrumen yang digunakan untuk menunjang pengumpulan data pada audit energi yang dilakukan adalah environmental meter, laser distance meter, tang amper, taspen dan smart monitoring energi.

\section{Tahapan Penelitian}

Tahapan penelitian dimulai dari mengumpulkan data historis sistem kelistrikan, melakukan pengukuran dan analisis terhadap hasil perhitungan sebagai dasar dalam memberikan rekomendasi agar mendapatkan nilai IKE yang efisien dalam rangka konservasi dan efisiensi energi listrik digedung A FT-UNILA

\section{Data Historis Sistem Kelistrikan}

Pada tahapan ini, data yang dikumpulkan adalah data sistem kelistrikan serta sumber energi listrik pada gedung A FT UNILA yang dapat digambarkan seperti gambar 1 berikut : 


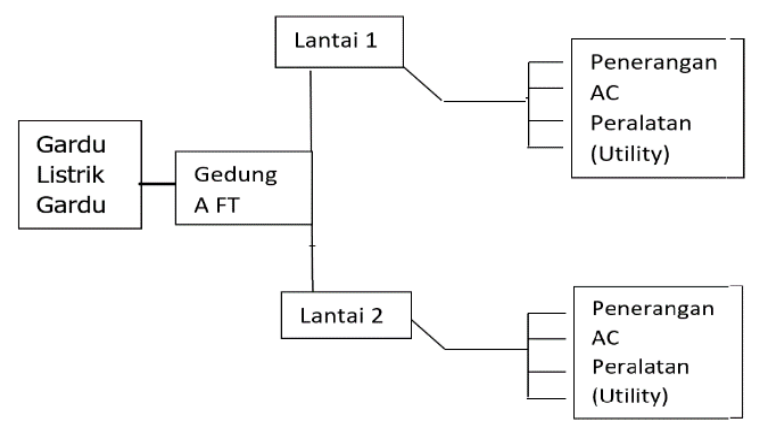

Gbr 1. Diagram Sistem Kelistrikan Gedung A Fakultas Teknik Universitas Lampung

2. Pengukuran Sistem Kelistrikan

Pengukuran dilakukan dalam rangka menghitung besarnya konsumsi energi listrik dan luas area. Hasil pengukuran digunakan dalam menghitung besarnya nilai IKE untuk selanjutnya dijadikan referensi untuk efisiensi penggunaan energi listrik[5]

\section{Perhitungan dan Analisis Hasil}

Tahapan ini adalah merupakan tahapan terakhir untuk mandapatkan nilai IKE. Perhitungan dilakukan dengan menggunakan persamaan (1), (2) dan (3). Beberapa asumsi juga diterapkan pada tahapan ini diantaranya lama jam penggunaan peralatan listrik dan umur peralatan listrik yang sudah tidak terssedia lagi datanya pada data historis sistem kelistrikannya.

\section{HASIL DAN PEMBAHASAN}

Sumber energi listrik utama pada gedung Fakultas Teknik Unila disuplai dari PLN, melalui gardu induk unila, selanjutnya dari gardu induk disalurkan ke beberapa gedung termasuk gedung A Fakultas Teknik Unila melalui panel tiap - tiap lantai dengan tegangan kerja $220 / 380 \mathrm{~V}, 50 \mathrm{~Hz}$, tidak ada meter listrik pada setiap gedung dan tidak ada gambar sistem kelistrikannya[10]

\section{A. Gambaran Umum Kondisi Besaran Listrik}

Gambaran umum besaran listrik seperti pada gambar. 2 didapatkan dengan melakukan pengukuran menggunakan prototype smart monitoring besaran listrik.

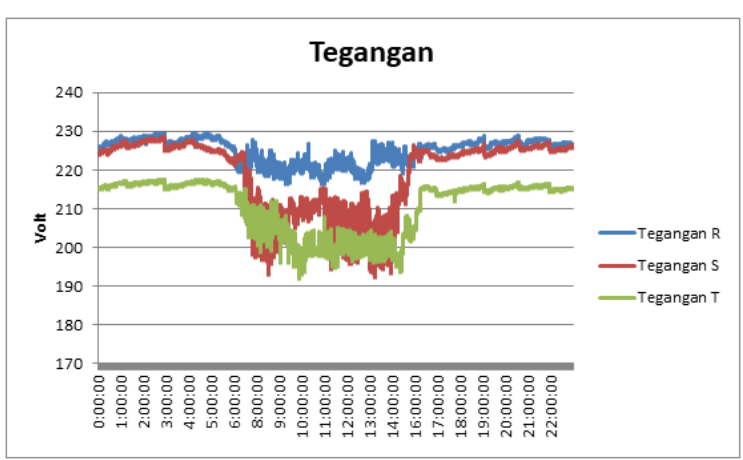

(a) Grafik Tegangan (Volt)

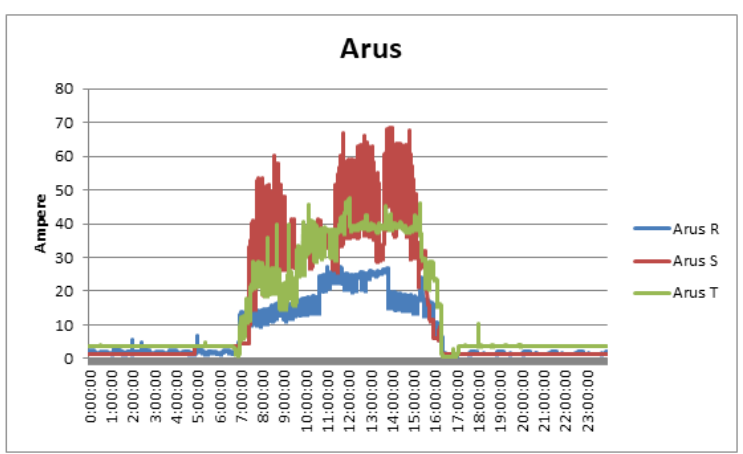

(b) Grafik Arus (Amper)

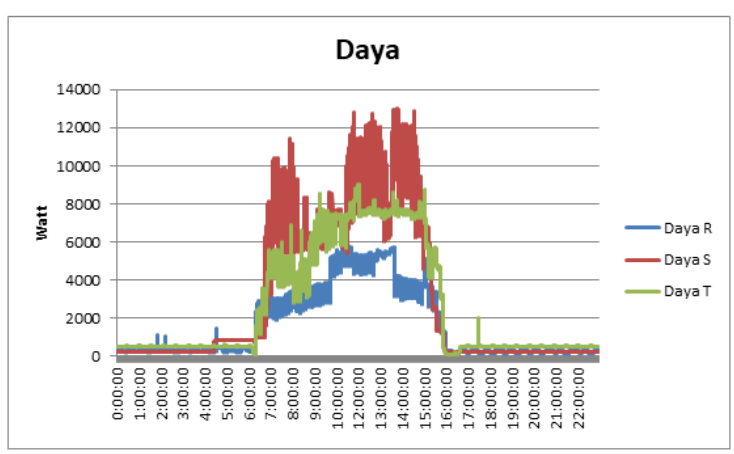

(c) Grafik Daya (Watt)

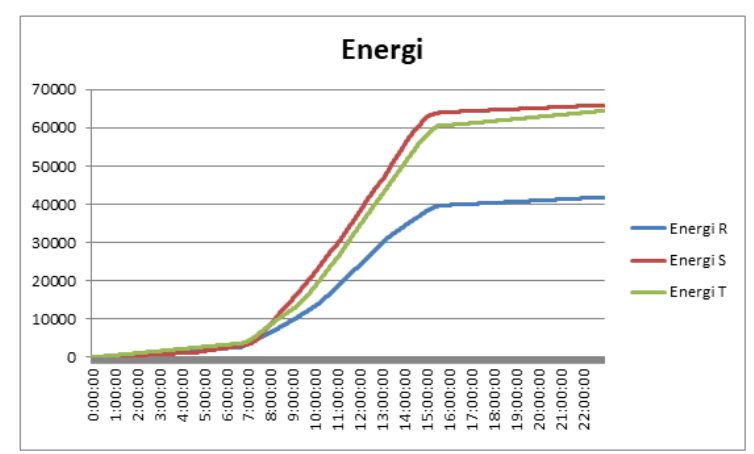

(d) Konsumsi Energi (Kwh)

Gbr 2. Grafik Monitoring Besaran Listrik pada Gedung A Fakultas Teknik Universitas Lampung 
Dari grafik yang digambarkan pada gambar. 2, dapat dijelaskan bahwa kondisi sistem kelistrikan pada gedung A FT Unila masih pada kondisi normal. Variasi tegangan masih memenuhi standar yang ditetapkan PLN $\pm 10 \%$ dari 220 Volt yang ditetapkan PLN, seperti terlihat pada gambar 2(a).

Kondisi Arus dan daya pada gambar 2(b) dan 2(c) terlihat adanya peningkatan pada saat jam kerja (jam 08.00 WIB sampai jam 16.00 WIB). Hal ini dimungkinkan karena Fakultas Teknik Unila memang melakukan aktifitas perkantoran pada jam tersebut. Selanjutnya pada gambar 2(d) yang merupakan gambaran pola konsumsi energi juga dapat dilihat mengikuti pola Arus dan Daya yaitu cenderung mengalami peningkatan signifikan pada saat jam kerja. Hal yang menarik pada hasil pengukuran ini adalah dari gambar. 2 terlihat adanya kecenderungan antara fasa $\mathrm{R}, \mathrm{S}$ dan $\mathrm{T}$ cenderung tidak seimbang. Hal ini perlu menjadi perhatian agar jika ada penambahan beban pada masa datang diusahakan pada fasa yang jumlah bebannya masih rendah dalam hal ini adalah fasa $\mathrm{R}$ yang bertujuan agar tidak terjadi adanya ketidakseimbangan arus yang melampaui batas yang diizinkan.

\section{B. Hasil Audit Energi}

Dengan menggunakan data hasil pengukuran dan asumsi penggunaan peralatan listrik rata rata adalah 8 jam (sesuai jam kerja) maka diperoleh nilai IKE sebagai berikut :

Tabel 2. Nilai IKE

\begin{tabular}{|l|l|l|l|l|l|l|}
\hline No & Lt. & $\begin{array}{c}\text { Energi } \\
\text { listrik } \\
\text { /hari } \\
\mathbf{k W h}\end{array}$ & $\begin{array}{c}\text { Energi/ } \\
\text { bulan } \\
\mathbf{( k W h )}\end{array}$ & Luas & $\begin{array}{c}\text { IKE/ } \\
\text { Bulan }\end{array}$ & $\begin{array}{c}\text { Status } \\
\text { AC }\end{array}$ \\
\hline 1 & Lt.1 & 234,3 & 5156 & 512,4 & 10,0 & Efisien \\
\hline 2 & Lt.2 & 256,3 & 5639,3 & 632,6 & 8,9 & Efisien \\
\hline \multicolumn{2}{|l}{ Total } & 490,6 & 10795,3 & 1144,0 & 9,4 & Efisien \\
\hline
\end{tabular}

Berdasarkan tabel 1, menurut Peraturan Menteri ESDM No.13 Tahun 2012 maka penggunaan energi di Gedung A FT Unila termasuk kategori efisien dengan nilai IKE 9,487 kwh/m2/bulan. Namun demikian berdasarkan pengamatan di lapangan masih ditemukan adanya pemborosan-pemborosan dalam penggunaan maupun pengoperasian peralatan listrik yang tidak sesuai standar, sehingga beberapa rekomendasi diberikan pada penelitian ini diantaranya adalah

1. Meningkatkan maintenance lampu yaitu mengganti lampu yang sudah habis masa pakainya dan membersihkan armature lampu sacara berkala.

2. Mengatur temperatur pada remote $\mathrm{AC}$ di seluruh ruangan pada suhu $24-27^{\circ} \mathrm{C}$

3. Housekeeping (Perawatan) AC setiap 3 bulan sekali

4. Menutup pintu dan jendela ketika AC sedang dinyalakan

5. Memasang door closer pada pintu-pintu setiap ruangan lebih utama yang berhubungan langsung dengan lingkungan luar.

6. Pengoptimalan waktu penggunaan AC

Jika Rekomendasi ini dapat dilaksanakan, maka dengan menggunakan pesamaan (1) nilai IKE dapat bergeser menjadi sangat efisien dengan rincian sebagai berikut :

Tabel 3. Nilai IKE Setelah Rekomendasi

\begin{tabular}{|l|l|l|l|l|l|l|}
\hline No & Lt & $\begin{array}{c}\text { Energi } \\
\text { listrik } \\
\text { /hari } \\
\text { (kWh) }\end{array}$ & $\begin{array}{c}\text { Energi } \\
/ \text { bln } \\
\mathbf{( k W h )}\end{array}$ & Luas & $\begin{array}{c}\text { IKE/ } \\
\text { bln }\end{array}$ & $\begin{array}{c}\text { Status } \\
\text { AC }\end{array}$ \\
\hline 1 & $\begin{array}{l}\text { Lt. } \\
1\end{array}$ & 203,8 & 4485 & 512,4 & 8,7 & Efisien \\
\hline 2 & $\begin{array}{l}\text { Lt. } \\
2\end{array}$ & 232,8 & 5121,7 & 632,6 & 8,0 & $\begin{array}{c}\text { Sangat } \\
\text { Efisien }\end{array}$ \\
\hline \multicolumn{2}{|l|}{ Total } & 436,6 & 9606,7 & 1145 & 8,3 & $\begin{array}{c}\text { Sangat } \\
\text { Efisien }\end{array}$ \\
\hline
\end{tabular}

Nilai IKE Rekomendasi seperti tabel 3 dapat menjadi sangat efisien yaitu mencapai nilai $8,424 \mathrm{kwh} / \mathrm{m}^{2} / \mathrm{bulan}$.

\section{KESIMPULAN}

Audit energi perlu dilakukan dalam rangka mengetahui efesiensi penggunaan energi listrik pada suatu gedung. Dari audit energi yang dilakukan pada gedung A FT UNILA diketahui bahwa besaran listrik yang terukur ( tegangan, arus, daya dan energi) masih dalam batasan yang diizinkan, walaupun ada ketidakseimbangan pembebanan disetiap fasanya. Penggunaan energi listrik mengikuti pola jam kerja perkantoran terlihat dari meningkatnya jumlah arus, daya dan energi pada saat jam kerja tersebut. Berdasarkan nilai IKE yang 
diperoleh dari hasil perhitungan pada gedung A FT UNILA adalah $9,487 \mathrm{kwh} / \mathrm{m}^{2} /$ bulan. Nilai ini termasuk kategori efisien. Nilai IKE ini masih bisa ditingkatkan menjadi sangat efisien mencapai $8,424 \mathrm{kwh} / \mathrm{m}^{2} / \mathrm{bulan}$ dengan menerapkan beberapa rekomendasi yang diusulkan.

\section{UCAPAN TERIMA KASIH}

Terimakasih diucapkan kepada Universitas Lampung yang telah memberikan hibah penelitian DIPA-BLU Fakultas Teknik Unila, Dekan Fakultas Teknik dan semua pihak yang telah meberikan izin serta data yang berkenaan dengan penelitian audit ini.

\section{REFERENSI}

[1] Republik Indonesia. 2007. Undang Undang No 30 Tahun 2007 tentang Energi. Lembaran Negra Republik Indonesia Tahun 2007 Nomor 96. Jakarta.

[2] Republik Indonesia. 2012.Peraturan Menteri ESDM No. 13 Tahun 2012 Tentang Penghematan Pemakaian Energi Listrik. Berita Negara Republik Indonesia Tahun 2012 Nomor 556. Jakarta.

[3] Republik Indonesia. 2012. Peraturan Menteri ESDM No. 14 Tahun 2012 Tentang Manajemen Energi. Berita Negara Republik Indonesia Tahun 2012 Nomor 557. Jakarta.

[4] Jati U., Heri G., Nining P.(2014) "Audit Energi dan Analisis Penghematan Konsumsi Energi pada Sistem Peralatan Listrik di Gedung Pelayanan Unila".Vol. 8. No. 2
[5] Dikpride D., Meizano A. M., Najib A., Gigih F. N., Yul M., (2019), Dasboard Pengawasan Besaran Listrik Waktu Nyata, Barometer, Volume 4 No.1, Januari 2019, 1-4

[6] Dikpride D., Ady K., Muhammad K., Mardiana, Gigih F. N.(2015) Smart Monitoring of Electrical Quantities Based on Single Board Computer BCM2835, Proceeding of 2015 2nd Int. Conference on Information Technology, Computer and Electrical Engineering (ICITACEE), Indonesia.

[7] 7Dikpride D., Gigih F. N., Meizano A. M., Agus S. (2018), Monitoring dan Manajemen Energi Listrik Gedung Laboratorium Berbasis Internet of Things (IoT), Prosiding Seminar Nasional Teknik Elektro, Malang.

[8] Avrin N. W., Sasongko P. H. , Bayu A. J. (2017), Audit Energi pada Gedung Departemen Teknik Arsitektur dan Perencanaan FT UG, Proseding Seminar Nasional The 9th Conference on Information Technology and Electrical Engineering, Yogyakarta

[9] H.Hayt. William, dkk (2005), Rangkaian Listrik, jilid 1, Jakarta: Erlangga.

[10] PT. Energi Management Indonesia.2016. Laporan Audit Gedung $\mathrm{H}$ Jurusan Teknik Elektro FT Unila.Bandar Lampung 